\title{
Pigmentary and Other Dermatologic Manifestations of Minocycline: a reminder of adverse effects
}

\author{
Kayla Rodriguez, BS ${ }^{1}$, Courtney Wellman, MD' , Adam M. Franks, MD', \\ Kimberly McClelland, MD, MPH, MBA' ${ }^{1}$, Tammy Bannister, MD' ${ }^{1}$
}

Author affiliations are listed at the end of this article.

The applications of the tetracycline class of antibiotics extend beyond their antimicrobial activity to anti-inflammatory, immunosuppressive and neuroprotective applications, making it a commonly used class of medication. Minocycline, a second-generation tetracycline, has inherent characteristics that improve absorption and distribution. These benefits promote even more widespread use. This familiarity of usage breeds prescriptive complacency toward the dermatologic complications including hyperpigmentation. The following case explores these adverse manifestations of minocycline use.
Correspondence to: Adam M. Franks, MD Marshall Unviersity Joan C. Edwards School of Medicine franks1@marshall.edu

\section{KEYWORDS}

Minocycline, Minocycline Toxicity, Hyperpigmentation

\section{INTRODUCTION}

Since the 1950s, the broad-spectrum antibiotic tetracycline, a polyketide from the Streptomyces genus of Actinobacter, ${ }^{1}$ has commonly been used to treat both gram-positive and gram-negative bacterial infections. ${ }^{2,3}$ The tetracycline family are bacteriostatic, ${ }^{2}$ halting the reproduction of bacterial cells by inhibiting protein synthesis via binding to the 30s-ribosomal subunit. ${ }^{2-4}$ In addition to their antimicrobial abilities, tetracyclines demonstrate neuroprotective, anti-inflammatory and immunosuppressive properties, ${ }^{2,5,6}$ allowing this class to treat other conditions including rosacea and rheumatoid arthritis., Minocycline, along with doxycycline, is a second-generation semi-synthetic tetracycline ${ }^{1,4,5,8-12}$ which was developed with improved absorption and lipophilicity allowing both oral and intravenous administration. ${ }^{3}$

Although minocycline specifically has several advantageous properties over other tetracyclines, ${ }^{2}$ it has been documented to have a variety of adverse reactions including nausea, vomiting, dizziness, ${ }^{1,2,8-10}$ hepatotoxicity, ${ }^{1,2,6,9-11,13}$ vasculitis, ${ }^{4,6}$ organ dysfunction ${ }^{1,8}$ (including polyarthritis, nephritis, pneumonitis, and pancreatitis), pseudotumor cerebri ${ }^{5,9,10}$ and medication-induced lupus. ${ }^{2,4,5,8-11}$ An uncommon yet unfortunate adverse reaction to minocycline, however, is pigmentation related and tends to occur more often when compared to other tetracyclines. ${ }^{2,7}$ In this case, these visible risks of minocycline are more closely examined.

\section{CASE PRESENTATION}

At a routine follow up visit for hypertension and hyperlipidemia, a 70-year-old white female with a history of ocular rosacea was noted to have "tanned skin." She denied excess sun exposure and a workup for causes of increased skin pigmentation was unfruitful for any metabolic source. Her medications at that time included doxycycline 100mg daily that had been prescribed for ocular rosacea by her ophthalmologist consistently for 4 years. She was informed of the suspected source of the skin changes and advised to stop doxycycline and discuss 
alternative treatment with the prescribing physician.

Three years later, she presented with a sixmonth history of diarrhea and fatigue. Increased pigmentation on her forehead and cheeks bilaterally was also noted. Physical examination was unremarkable except for generalized hyperpigmentation and blue/black discoloration over the maxillary and temporal areas of her face (Picture 1). The medication review revealed that she had been started on minocycline treatment for ocular rosacea after her doxycycline was discontinued. Evaluation for causes of hyperpigmentation, fatigue, and diarrhea was again negative. She was advised to stop the minocycline. On repeat examinations, not only did her fatigue and diarrhea improve, but the intensity of the hyperpigmentation also minimally improved.

\section{DISCUSSION}

\section{Pharmacokinetics}

Compared to the older first-generation tetracyclines, minocycline's pharmacokinetic profile shows some clear advances. Minocycline (7-dimethylamino-6demethyl-6-deoxytetracycline) differs structurally from tetracycline by the addition of a dimethylamino group at the seventh carbon. ${ }^{6}$ Due to its lipid solubility, its absorption rate between the stomach and jejunum is $95-100 \%$ in all populations, including the elderly, regardless of food intake..$^{2-4,7,10}$ Concomitant iron and antacids containing calcium and magnesium, however, can reduce the absorption. ${ }^{3}$ Its lipophilic nature not only promotes wide distribution in tissues, allowing crossing

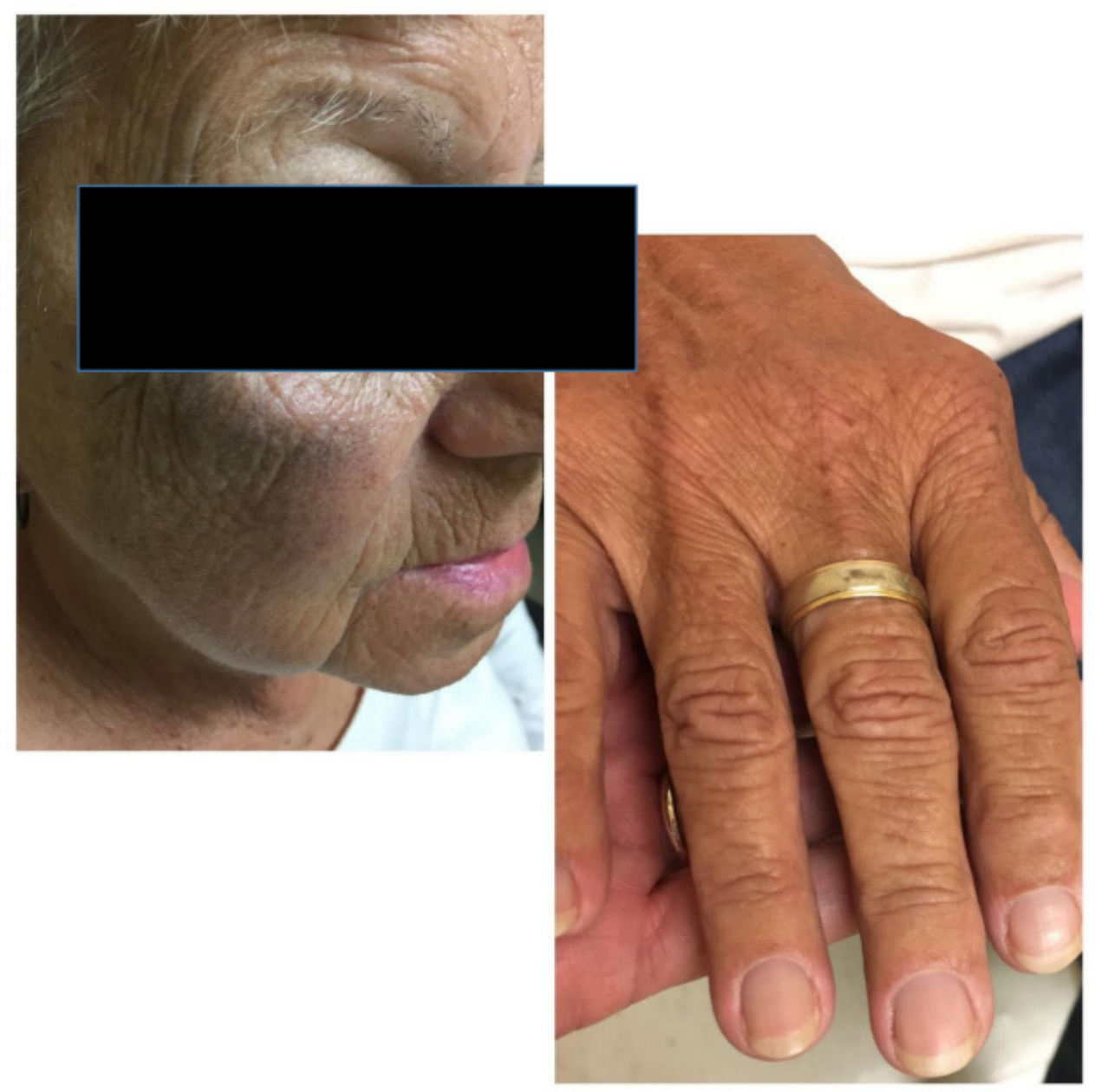

PICTURE 1: Demonstrates the generalized brownish pigmentation to the face, neck, and hand of a Type III reaction (case-patient). 
of the blood-brain barrier, ${ }^{2,3,7,14}$ but also reduces resistance. ${ }^{10,15}$ Three quarters of the medication is protein bound. ${ }^{3,7}$ Maximal dose is reached within 2 hours, with a dose-dependent variability and a half-life of 12-18 hours. ${ }^{2,3,10,12,15,16}$ The renal clearance of minocycline is $1.2-2.2 \mathrm{ml} / \mathrm{min}$ with $5-12 \%$ of the drug excreted in the urine and $20-35 \%$ eliminated in feces.3 Minocycline produces six metabolites with antimicrobial activity furthering its effectiveness. ${ }^{3}$ This unusual metabolism may also contribute to its unique adverse effects, such as abnormal pigmentation, which is observed in patients with long term minocycline use. ${ }^{6}$

\section{Pigmentary Changes in Minocycline Use}

Minocycline is routinely prescribed as $100 \mathrm{mg}$ daily with the highest dose recommendations by the Federal Drug Administration being 200 mg daily to avoid side effects. ${ }^{2,9}$ Hyperpigmentation is the most common side effect from the cumulative administration of minocycline ${ }^{7}$ and is often blamed on its rapid absorption and longer half-life. ${ }^{15}$ The classic pigmentation presentation patterns have been classified into four separate types (Table 1). Type 1 demonstrates a blue-black pigmentation primarily around areas of previous scarring or

\begin{tabular}{|c|c|c|c|c|}
\hline $\begin{array}{c}\text { Hyperpigmentation } \\
\text { Type }\end{array}$ & I & II & III & IV \\
\hline Presentation & $\begin{array}{l}\text { Blue Pigment in } \\
\text { areas of } \\
\text { previous } \\
\text { scarring and } \\
\text { inflammation }\end{array}$ & $\begin{array}{l}\text { Blue, black or } \\
\text { gray pigment in } \\
\text { areas of normal } \\
\text { skin usually on } \\
\text { the shins, } \\
\text { ankles, and } \\
\text { arms }\end{array}$ & $\begin{array}{c}\text { Generalized } \\
\text { brown pigment } \\
\text { in sun-exposed } \\
\text { areas diffusely }\end{array}$ & $\begin{array}{l}\text { Blue or gray } \\
\text { pigment in areas } \\
\text { around the lips } \\
\text { or in areas of } \\
\text { scarring on the } \\
\text { posterior thorax }\end{array}$ \\
\hline Histology & $\begin{array}{c}\text { Degraded } \\
\text { products } \\
\text { chelated with } \\
\text { hemosiderin } \\
\text { and iron. } \\
\text { Pigment is seen } \\
\text { in perivascular } \\
\text { macrophages } \\
\end{array}$ & $\begin{array}{l}\text { Minocycline } \\
\text { and oxidation } \\
\text { products } \\
\text { chelated to iron. } \\
\text { Pigment bound } \\
\text { in membrane } \\
\text { dermis }\end{array}$ & $\begin{array}{l}\text { Minocycline- } \\
\text { melanin } \\
\text { complex. } \\
\text { Pigment bound } \\
\text { in basal layer } \\
\text { epidermis and } \\
\text { papillary dermis }\end{array}$ & $\begin{array}{c}\text { Post- } \\
\text { inflammatory } \\
\text { from a fixed } \\
\text { drug reaction }\end{array}$ \\
\hline Onset & Anytime & $\begin{array}{c}>100 \mathrm{~g} \\
\text { cumulative dose }\end{array}$ & $\begin{array}{c}>100 \mathrm{~g} \\
\text { cumulative dose }\end{array}$ & Anytime \\
\hline Treatment & $\begin{array}{l}\text { Discontinuation } \\
\text { of minocycline }\end{array}$ & $\begin{array}{l}\text { Discontinuation } \\
\text { of minocycline }\end{array}$ & $\begin{array}{c}\text { Discontinuation } \\
\text { of minocycline }\end{array}$ & $\begin{array}{c}\text { Discontinuation } \\
\text { of minocycline }\end{array}$ \\
\hline Duration & $\begin{array}{l}\text { Resolves after } \\
\text { months }\end{array}$ & $\begin{array}{l}\text { Resolves after } \\
\text { months }\end{array}$ & $\begin{array}{l}\text { Most likely } \\
\text { permanent }\end{array}$ & $\begin{array}{l}\text { Resolves after } \\
\text { months }\end{array}$ \\
\hline
\end{tabular}

TABLE 1: Comparison of the different types of cutaneous pigmentary reactions to minocycline. From the large cumulative dose, generalized brownish coloration and lack of significant resolution after discontinuation of the minocycline, the case-patient clearly had a type III reaction. 
inflammation. ${ }^{7,9,12,15}$ Under microscopy, perivascular macrophages laden with granules of pigment chelated with iron, hemosiderin, and ferritin are seen. ${ }^{7,15}$ The pigmentation does not correspond to either duration or cumulative dose of minocycline..$^{9,15}$ Therefore, it may be more rapidly seen but also resolves with discontinuation of the medication. .,15 $^{2}$ The Type 2 variant is diffuse, presenting as blue, black or gray discoloration on the shins, arms, and ankles. $^{7,12,15}$ It is dose-dependent, associated with a lifetime accumulation of $70 \mathrm{~g}-100 \mathrm{~g}$ of minocycline. It takes longer to present and months to resolve after discontinuation of the medication., ${ }^{7,124,15}$ Minocycline oxidative degradation products chelated with iron can be observed microscopically as a membranebound pigment collection in the dermis and subcutis or free in collagen fibers. ${ }^{7,15}$ Laser treatment can speed resolution by fragmenting both intracellular and extracellular pigments to aid drainage by the lymphatic system. Only mild desquamation and transient purpura are seen as adverse events of this treatment. ${ }^{12}$ Type 3 reactions are unique compared to Types 1 and 2 because microscopically the pigmentation is composed of minocycline-melanin complexes. ${ }^{7,15}$ This presents as a generalized brown coloration at sun-exposed sites.,12,15 This too is a cumulative effect, $7,9,14,15$ as is type 2 , but it is more likely to be permanent with less efficacy of laser treatments., ${ }^{72}$ Type 4 pigmentation is similar to Type 1 but has been described as an independent phenotype, appearing as either a bluish pigmentation of the lips or blue-black pigmented scarring on the posterior thorax. Microscopically it differs slightly in that the pigment seems postinflammatory from a resolving fixed drug reaction. ${ }^{7,15}$

\section{Other Dermatologic Manifestations of Minocycline}

Adverse dermatologic and pigmentary reactions to minocycline can occur outside of these four classic types (Table 2). Multiple cases of hyperpigmentation occurring at the skin, $, 10,14$ nail beds, ${ }^{7}$ teeth, 7,9 bones, $^{7,9,14}$ cartilage, $^{7,9}$ mucus membranes, ${ }^{7,9}$ thyroid, ${ }^{7,9}$ tongue, ${ }^{7,10,14}$ sclera, ${ }^{7,9}$ cardiac valves ${ }^{9}$, and breast milk7 have been documented. There are multiple theories pertaining to the cause of hyperpigmentation. These include the formation of insoluble salts from minocycline degradation, siderosis, accumulation of black degradation products at different tissue locations, melanocyte enhancement, and derivatives of minocycline forming complexes chelated to iron, melanin, and calcium., ${ }^{9} 10,12,15$ Other non-pigmentary dermatologic changes can occur from minocycline exposure, including urticaria caused by vasoactive amines released from mast cells during a hypersensitivity reaction, ${ }^{1,2,5,11}$ subcutaneous nodules and livedo reticularis from polyarteritis nodosa ${ }^{4,6,11}$ vasculitis, ${ }^{6,11}$ denudation and hemorrhagic changes of StevensJohnson Syndrome, ${ }^{4}$ as well as erythema in sunexposed areas from photosensitivity rashes. ${ }^{4}$

\begin{tabular}{|l|l|}
\hline \multicolumn{1}{|c|}{ Reaction Site } & \multicolumn{1}{c|}{ Mechanism of Disease and/or Clinical Presentation } \\
\hline Bone & $\begin{array}{l}\text { Occurs as a result of accumulated deposits chelated with iron, calcium } \\
\text { and hemosiderin. }\end{array}$ \\
\hline Breast Milk & $\begin{array}{l}\text { Lipophilic nature facilitates the accumulation of macrophages with } \\
\text { iron complexes. }\end{array}$ \\
\hline Cartilage & $\begin{array}{l}\text { Occurs as a result of accumulated deposits chelated with iron, } \\
\text { calcium, and hemosiderin. }\end{array}$ \\
\hline Eyes & $\begin{array}{l}\text { Blue-Gray discoloration occurs in the conjunctiva and sclera from a } \\
\text { Type III-like hyperpigmentation mechanism. }\end{array}$ \\
\hline Mucous Membranes & $\begin{array}{l}\text { Rare. Only occurs with minocycline. Areas of trauma demonstrate } \\
\text { complexes with iron or calcium. }\end{array}$ \\
\hline Nails & $\begin{array}{l}\text { Graying of the proximal nailbed by a Type III-like hyperpigmentation } \\
\text { pathology. Less common than skin manifestations. }\end{array}$ \\
\hline Teeth & $\begin{array}{l}\text { Occurs 6\% of the time. Permanent blue-gray discoloration. Enamel is } \\
\text { etched. }\end{array}$ \\
\hline Thyroid Gland & Oxidation by thyroid peroxidase as a result of long-term use. \\
\hline
\end{tabular}

TABLE 2: Catalogue of the potential pigmentary manifestations of minocycline. 
Patient

Interestingly, patients being treated for rosacea have a higher chance of abnormal pigmentation than those being treated for routine acne, ${ }^{7,15}$ as they are usually older and have received higher cumulative doses of minocycline than the younger patients treated for acne vulgaris. ${ }^{7}$ In this case, the patient was treated for rosacea first with doxycycline, followed by minocycline with an estimated cumulative dose of over 100 grams of minocycline in the three years after the tetracycline was discontinued. Not surprisingly, she developed a Type III reaction from the minocycline cumulative dose. Also, not surprisingly, she has shown very little improvement after discontinuation.

\section{CONCLUSION}

The frequency with which Minocycline is used casts it in a light that makes it seem benign. Whether it is pigment deposition or stimulating a dermatologic process, its effect on the patient can be significant and permanent. Remembering the possible ramifications will allow physicians to better inform their patients during its use.

\section{AUTHOR AFFILIATIONS}

1. Marshall University Joan C. Edwards School of Medicine, Huntington, West Virginia

\section{REFERENCES}

1. Jang JW, Bae Y-J, Kim YG, et al. A case of anaphylaxis to oral minocycline. Journal of Korean Medical Science. 2010;25(8):1231-1233.

2. Garrido-Mesa N, Zarzuelo A, Gálvez J. Minocycline: far beyond an antibiotic. British Journal of Pharmacology. 2013;169(2):337-352.

3. Agwuh KN. Pharmacokinetics and pharmacodynamics of the tetracyclines including glycylcyclines. Journal of Antimicrobial Chemotherapy. 2006;58(2):256-265.

4. Culver B, Itkin A, Pischel K. Case report and review of minocycline-induced cutaneous polyarteritis nodosa. Arthritis \& Rheumatism.
2005;53(3):468-470.

5. Losanoff JE, Holder-Murray JM, Ahmed EB, Cochrane AB, Testa G, Millis JM. Minocycline toxicity requiring liver transplant. Digestive Diseases and Sciences. 2007;52(11):3242-3244.

6. Lenert $\mathrm{P}$, Icardi M, Dahmoush L. ANA (+) ANCA $(+)$ systemic vasculitis associated with the use of minocycline: case-based review. Clinical Rheumatology. 2013;32(7):1099-1106.

7. Eisen D, Hakim MD. Minocycline-induced pigmentation. Drug Safety. 1998;18(6):431-440.

8. Colvin JH, Sheth AP. Minocycline hypersensitivity syndrome with hypotension mimicking septic shock. Pediatric Dermatology. 2001;18(4):295298.

9. Goulden V, Glass D, Cunliffe W. Safety of longterm high-dose minocycline in the treatment of acne. British Journal of Dermatology. 1996;134(4):693-695.

10. Somech R, Arav-Boger R, Assia A, Spirer Z, Jurgenson $U$. Complications of minocycline therapy for acne vulgaris: case reports and review of the literature. Pediatric Dermatology. 1999;16(6):469-472.

11. Schrodt BJ, Kulp-Shorten CL, Callen JP. Necrotizing vasculitis of the skin and uterine cervix associated with minocycline therapy for acne vulgaris. Southern Medical Journal. 1999;92(5):502-504.

12. Biswas A. The peculiar case of a blue man. Journal of Postgraduate Medicine. 2015;61(2):140.

13. Bocker R, Estler CJ, Ludewig-Sandig D. Evaluation of the hepatotoxic potential of minocycline. Antimicrobial Agents and Chemotherapy. 1991;35(7):1434-1436.

14. Kerbleski GJ, Hampton TT, Cornejo A. Black bone disease of the foot: a case study and review of literature demonstrating a correlation of long-term minocycline therapy and bone hyperpigmentation. The Journal of Foot and Ankle Surgery. 2013;52(2):239-241.

15. Zuckerman MD, Boyle KL, Rosenbaum CD. Minocycline toxicity: case files of the University of Massachusetts Medical Toxicology Fellowship. Journal of Medical Toxicology. 2012;8(3):304-309.

16. Shaughnessy KK, Bouchard SM, Mohr MR, Herre JM, Salkey KS. Minocycline-induced drug reaction with eosinophilia and systemic symptoms (DRESS) syndrome with persistent 
myocarditis. Journal of the American Academy of

Dermatology. 2010;62(2):315-318. 